\title{
Fe-Th (Iron-Thorium)
}

\section{H. Okamoto}

The Fe-Th phase diagram in [Massalski2] was redrawn from [1989Pal] and accepted in the assessment of [19930ka]. [2008Wan] attempted to reproduce this phase diagram by thermodynamic modeling. The result is shown in Fig. 1 and believed to be a better representation of the experimental data of [1989Pal] than the original drawing.

\section{References}

1989Pal: A. Palenzona and S. Cirafici, Alloying Behavior of Thorium with $\mathrm{Fe}, \mathrm{Co}$, and Ni, Thermochim. Acta, 1989, 162, p $117-125$
1993Oka: H. Okamoto, Fe-Th (Iron-Thorium), Phase Diagrams of Binary Iron Alloys, H. Okamoto, Ed., ASM International, Materials Park, OH, 1993, p 410-413

2008Wan: C.P. Wang, P. Yu, X.J. Liu, I. Ohnuma, R. Kainuma, and K. Ishida. Thermodynamic Assessment of the Co-Th and Fe-Th Systems, J. Alloys Compd., 2008, 457, p $150-156$

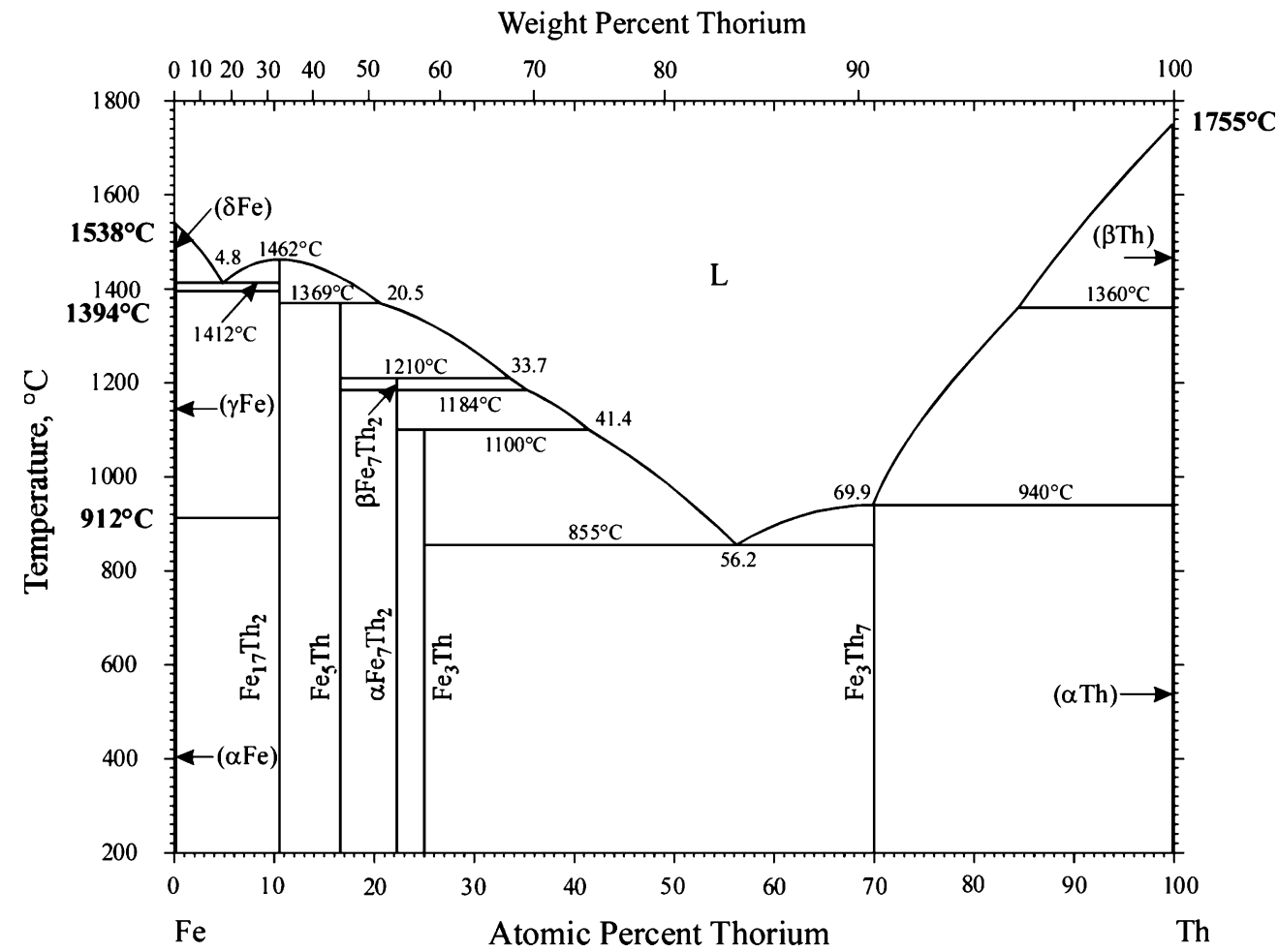

Fig. 1 Fe-Th phase diagram 